\title{
Serological evaluation of the role of cytomegalovirus in the pathogenesis of IDDM: a prospective study
}

\author{
M. Hiltunen ${ }^{1}$, H. Hyöty ${ }^{1}$, J. Karjalainen ${ }^{2}$, P.Leinikki ${ }^{3}$, M.Knip ${ }^{2}$, R.Lounamaa ${ }^{4}$, H.K. Åkerblom ${ }^{5}$ \\ and the Childhood Diabetes in Finland Study Group* \\ ${ }^{1}$ Department of Biomedical Sciences, University of Tampere, Tampere, Finland \\ ${ }^{2}$ Department of Pediatrics, University of Oulu, Oulu, Finland \\ ${ }^{3}$ Department of Chronic Virus Diseases, National Public Health Institute, Helsinki, Finland \\ ${ }^{4}$ Department of Epidemiology and Health Promotion, National Public Health Institute, Helsinki, Finland; the Children's Hospital, \\ University of Helsinki, Helsinki, Finland \\ ${ }^{5}$ The Children's Hospital, Second Department of Pediatrics, University of Helsinki, Helsinki, Finland
}

Summary To study the possible temporal association between primary cytomegalovirus infection and the appearance of islet cell autoantibodies or the development of insulin-dependent diabetes mellitus (IDDM) cytomegalovirus antibodies were analysed from follow-up sera of 46 initially non-diabetic siblings of diabetic children who either manifested clinical IDDM (22 siblings) or turned islet cell antibody positive (24 siblings) during the prospective observation (mean follow-up time 2.9 years). Secondly, cytomegalovirus antibodies were analysed during pregnancy in 96 mothers whose child presented with IDDM before the age of 7 years and in 96 control mothers who gave birth to a non-diabetic child. Thirdly, a case-control series including 90 newly-diagnosed young children with IDDM and their 90 control subjects was analysed. No seroconversions were found in cytomegalovirus antibodies during the follow-up of the 46 siblings indicating no temporal association with islet cell antibody seroconversion or manifestation of clinical diabetes. During the followup $17(37 \%)$ siblings were constantly seronegative and $29(63 \%)$ seropositive for cytomegalovirus IgG and there was no difference between islet cell antibody positive and negative siblings. Cytomegalovirus $\operatorname{IgG}$ and $\operatorname{IgM}$ were not different in pregnant mothers who gave birth to a subsequently diabetic child compared to control mothers, or in newly-diagnosed diabetic children compared to control children. Cytomegalovirus IgA was higher in newly-diagnosed diabetic children than in control children $(p<0.005)$. This difference disappeared when only cytomegalovirus IgG positive individuals were analysed. No correlation was found between islet cell antibodies and cytomegalovirus antibodies in newly-diagnosed diabetic patients. The results do not support the hypothesis that primary cytomegalovirus infections could initiate the cascade leading to autoimmune destruction of the beta cells. [Diabetologia (1995) 38: 705-710]

Key words Insulin-dependent diabetes mellitus, cytomegalovirus, pathogenesis, prospective study, ICA, siblings.
Received: 19 July 1994 and in final revised form: 14 December 1994

Corresponding author: Dr. M. Hiltunen, Department of Biomedical Sciences, University of Tampere, P. O. Box 607, SF33101 Tampere, Finland

* The Childhood Diabetes in Finland (DiMe) Study Group, see acknowledgements.

Abbreviations: IDDM, Insulin-dependent diabetes mellitus; ICA, islet cell autoantibodies; CMV, cytomegalovirus; EIA, enzyme immunoassay; EIU, enzyme immunoassay unit.
Primary cytomegalovirus (CMV) infections which may manifest before birth or very early in life are presumed to be always followed by persistent or recurrent infections or both [1]. It has been suggested that CMV infections may play a role in the pathogenesis of insulin-dependent diabetes mellitus (IDDM) by inducing or promoting the autoimmune process against beta cells. This has been supported by observations that the presence of the CMV genome and islet cell antibodies (ICA) are correlated in patients with newly-diagnosed IDDM [2], and that high titres of $\mathrm{IgG}$ class antibody against CMV are associated with ICA in healthy siblings of diabetic children [3]. 
Furthermore, immunological cross-reactivity between CMV and an islet cell $38 \mathrm{kDa}$ autoantigen has been described [4]. Characteristic inclusion bodies have been observed in islets of children with fatal $\mathrm{CMV}$ infections providing evidence that $\mathrm{CMV}$ may be able to cause direct damage in human beta cells $[5]$.

The present investigation is the first prospective study on the role of CMV in the pathogenesis of IDDM. CMV antibodies were analysed from followup sera taken repeatedly from originally non-diabetic siblings of diabetic children who either manifested clinical IDDM or became ICA positive during the follow-up. In addition, a series comprising pregnant mothers who gave birth to a child later manifesting IDDM as well as a case-control series of children with newly-diagnosed IDDM were analysed.

\section{Subjects and methods}

A population-based study of IDDM, called "Childhood Diabetes in Finland" (DiMe) - project included a prospective family study among non-diabetic siblings of newly-diagnosed diabetic patients (index cases) as well as access to sera taken from mothers during pregnancy with the children who contracted IDDM before the age of 7 years and matched control pregnancies. A case-control series of newly-diagnosed diabetic children younger than 7 years of age was additionally collected. The design of the study has been reported earlier in detail [6].

Subjects. The prospective family study among 3-19 year old siblings $(n=765)$ comprised blood sampling at 6 -month intervals immediately after the diagnosis of the index case. Of these siblings 22 presented with IDDM and 24 became ICA positive during the follow-up. The follow-up varied from 27 days to 6.3 years (mean 2.9 years) and in 33 cases $(72 \%$ ) the follow-up time was more than 2 years (Fig.1). The series of pregnant mothers comprised 96 mothers whose child presented with IDDM before the age of 7 years and 96 control mothers with a non-diabetic child matched for the time of delivery ( \pm 1 day) and the sex of the child. The maternal sera were obtained from the National Public Health Institute and were taken at the end of the third month of pregnancy originally for the routine rubella screening. The case-control study among young-onset cases with IDDM included 90 newly-diagnosed diabetic children under 7 years of age ( 39 children were born to the above-mentioned mothers) and their 90 unrelated age and sex matched control subjects ( 39 children were born to the above-mentioned control mothers). The mean age was 4.5 years and the number of male pairs was $48(53 \%)$. Sera were obtained at the diagnosis of clinical IDDM (on average within 7 days in patients and 59 days in control subjects) from all patients and control children and a couple of months later from 38 patient-control pairs (on average within 78 days in patients and 123 days in control children). In 11 of the 90 casecontrol pairs clinical IDDM was diagnosed before the age of 2 years. An additional 21 children with IDDM before the age of 2 years were also analysed.

Cytomegalovirus antibody enzyme immunoassay. Cytomegalovirus $\operatorname{IgG}$ and $\operatorname{IgM}$ were analysed using a commercial enzyme immunoassay (EIA) test (CMV IgG/IgM EIA, Labsystems,
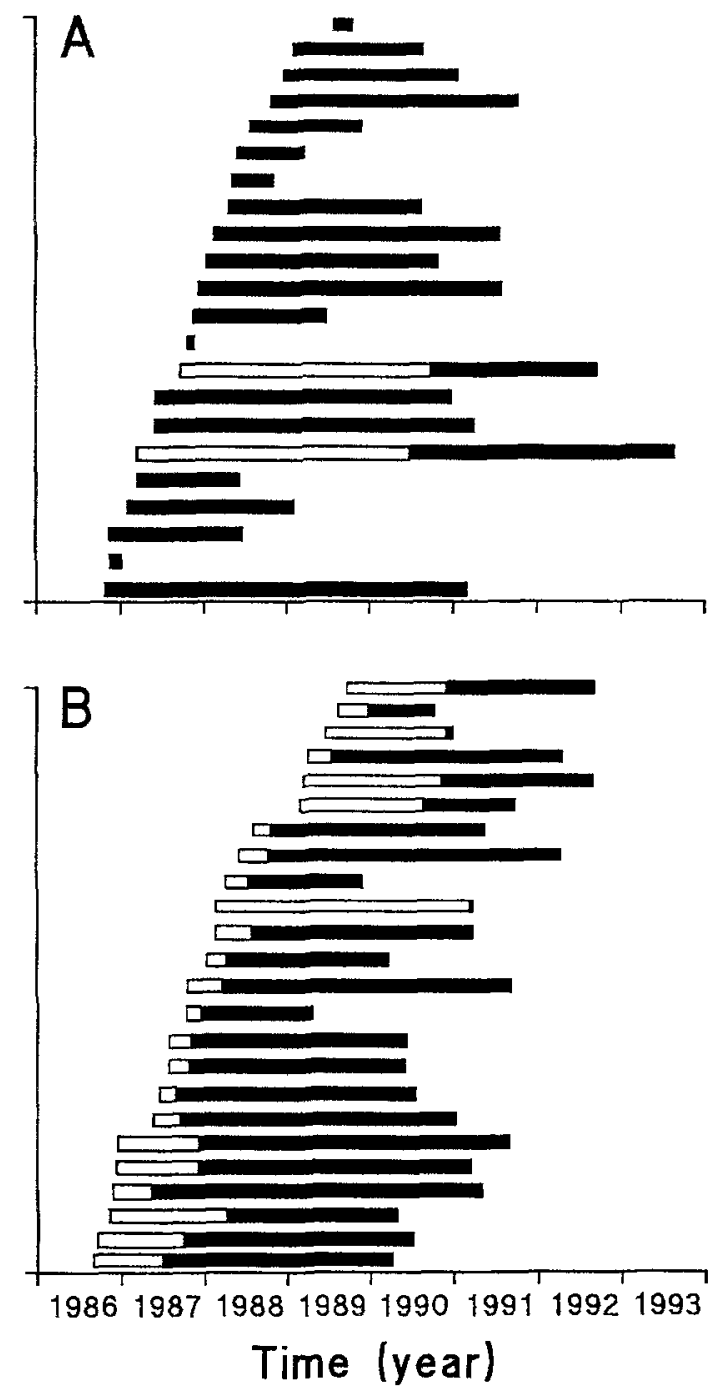

Fig. 1. $(\mathbf{A}, \mathbf{B})$ Duration and time of follow-up in 46 originally non-diabetic siblings of diabetic children: $(\mathbf{A})$ initially non-diabetic siblings who subsequently manifested IDDM (11 males and 11 females, mean age 7.7 years at the beginning of the follow-up); (B) non-diabetic siblings who turned ICA positive (14 males and 10 females, mean age 9.7 years at the beginning of the follow-up). Blank box, time before ICA seroconversion; solid box, time after ICA seroconversion

Helsinki, Finland). CMV IgA was analysed by peroxidase-conjugated anti-human IgA (Dako Immunoglobulins, Copenhagen, Denmark) as the second antibody layer. Antibody levels were expressed in enzyme immunoassay units (EIU) indicating the relative antibody activity of the sample compared to known positive and negative reference sera [7]. The cut-off limit for IgG positivity was $15 \mathrm{EIU}$, for IgM 40 EIU and for $\operatorname{IgA} 15$ EIU as deduced from the distribution of $\operatorname{IgG}$, IgM and IgA antibody levels in known positive and negative sera. All follow-up sera from one subject were analysed in one microtitre plate. Coded sera from mothers of a diabetic child and from the control mothers were similarly analysed in one microtitre plate as were the sera from newly-diagnosed diabetic children and corresponding control subjects. IgG seroconversions (de novo appearance of CMV IgG) were taken as an indicator of primary CMV infections. An additional IgM determination was done if a CMV IgG positive individual became ICA positive (de novo appearance of ICA) in the very beginning of the follow-up. In pregnant mothers the identification of recent pri- 
mary CMV infections was done by testing a single serum sample for CMV IgM and $\operatorname{IgG}$ [8]. In the case of $\operatorname{IgM}$ positivity avidity of CMV IgG antibodies was additionally determined; low avidity $(0-20 \%)$ is characteristic of a current primary CMV infection, borderline avidity $(21-35 \%)$ refers to a primary CMV infection during the past few months, and avidity over $35 \%$ to no primary CMV infection within the preceding 1-2 months [9].

Assay of ICA. Conventional ICA were determined by a standard indirect immunofluorescence test [10] and expressed in Juvenile Diabetes Foundation (JDF) units. The detection limit was 2.5 JDF units. Our ICA laboratory has participated in the international workshops on standardization of the ICA assay in which the sensitivity was $100 \%$, specificity $98 \%$, validity $98 \%$ and consistency $98 \%$ in the fourth round.

\section{Statistical analysis}

Two-tailed paired Student's $t$-test and McNemar's test were used in the statistical analyses of paired data. Correlation coefficients were calculated according to Spearman's method. As the distribution of CMV antibodies and ICAs were strongly skewed, ranks were used in the analyses of multiple regression. The analyses were done using SAS statistical software. The results are given as mean $\pm S E M$ if not otherwise indicated.

\section{Results}

Of the 46 prospectively followed siblings $29(63 \%)$ were originally seropositive and $17(37 \%)$ seronegative for CMV $\operatorname{IgG}$ and no seroconversions were seen during the observation period (Table 1). Twenty-two siblings manifested IDDM during the followup (mean follow-up 2.5 years). Half of them $(n=11)$ were seronegative for CMV IgG and remained that way until 2 months after the diagnosis of diabetes. The remaining $11(50 \%)$ siblings were constantly seropositive for CMV IgG showing no significant alterations in antibody levels. Twenty of those 22 pre-diabetic siblings were initially ICA positive and two were ICA negative but both became ICA positive during the follow-up. In one of them CMV IgG was constantly positive until the diagnosis of diabetes (altogether 5.1 years) and in the other constantly negative for 6.3 years. One of the 20 initially ICA-positive pre-diabetic siblings turned ICA negative before the manifestations of IDDM. Out of the 24 non-diabetic siblings who turned ICA positive, but did not present with diabetes, six $(25 \%)$ were CMV IgG seronegative and 18 (75\%) seropositive showing no seroconversions or significant alterations in CMV $\operatorname{IgG}$ levels during the follow-up. In 11 ( $46 \%$ ) of these siblings ICA positivity was only transient. None was CMV IgM positive in the subgroup of four CMV IgG positive siblings who ICA seroconverted in the very beginning of the follow-up (within 4 months). CMV IgA remained at
Table 1. The number of ICA positive and negative siblings at the start and at the end of the follow-up period according to CMV IgG antibody status ${ }^{\mathrm{a}}$

\begin{tabular}{|c|c|c|c|}
\hline & \multicolumn{3}{|c|}{ CMV IgG } \\
\hline & Positive & Negative & Total \\
\hline \multicolumn{4}{|c|}{ Siblings who manifested IDDM } \\
\hline ICA negative at start $(n)$ & 1 & 1 & 2 \\
\hline ICA positive at start $(n)$ & 10 & 10 & 20 \\
\hline ICA negative at end $(n)$ & 1 & 0 & 1 \\
\hline ICA positive at end $(n)$ & 10 & 11 & 21 \\
\hline \multicolumn{4}{|c|}{ Siblings who turned ICA positive } \\
\hline ICA negative at start $(n)$ & 18 & 6 & 24 \\
\hline ICA positive at start $(n)$ & 0 & 0 & 0 \\
\hline ICA negative at end ( $n$ ) & 9 & 2 & 11 \\
\hline ICA positive at end ( $n$ ) & 9 & 4 & 13 \\
\hline
\end{tabular}

${ }^{a}$ ICA positivity did not persist to the end of the observation period in one sibling who manifested IDDM and in 11 siblings who ICA seroconverted

constant levels showing no increases in association with ICA seroconversion or the diagnosis of diabetes.

In the series of pregnant mothers whose child contracted IDDM before the age of 7 years, 71 of 96 (74\%) had CMV IgG antibodies at the end of the first trimester of the pregnancy compared to 78 of 96 $(81 \%)$ of control mothers (NS). CMV IgG levels were also not statistically different between the two groups (104 \pm 7 and $112 \pm 7$ EIU, respectively). Low levels of CMV IgM were found in three mothers with a diabetic child (40 EIU, 47 EIU, 64 EIU) and two control mothers (78 EIU, 42 EIU) who were all further analysed for the avidity of CMV IgG. Two mothers with a diabetic child and two control mothers had CMV IgG antibodies of high avidity (over $35 \%$ ) and one mother with a diabetic child had a borderline avidity of $35 \%$.

Among newly-diagnosed diabetic children CMV IgG was found in 42 of $90(47 \%)$ cases and in the matched control children in 38 of $90(42 \%)$ cases (NS). Only one of the patients had seroconversion in CMV IgG between the first and second serum sample. Four patients $(4 \%)$ and four control children were positive for CMV IgM (NS). The levels of CMV IgG or IgM were not different between the patients and control subjects (Table 2). The proportion of CMV IgA positive patients was $39 \%$ (35 of 90) which was significantly higher $(p<0.005)$ than that in control children $(16 \%, 14$ of 90$)$ and also the mean level of $\operatorname{Ig}$ A was significantly higher in patients than in control children (Table 2). This difference in $\operatorname{Ig} \mathrm{A}$ antibodies was more pronounced in females $(16 \pm 2$ vs $9 \pm 1$ EIU, $p<0.005)$ than in males $(14 \pm 2$ vs $10 \pm 2$ EIU, NS). CMV IgA was not, however, different when only IgG positive patients were compared to their IgG positive control subjects (17 pairs, $13 \pm 2$ vs $12 \pm 2$ EIU). In 14 of $90(16 \%)$ diabetic pa- 
Table 2. CMV IgG, IgM and IgA in three different age groups in patients with newly-diagnosed IDDM and in age- and sexmatched control children

\begin{tabular}{|c|c|c|c|c|c|c|c|c|}
\hline \multicolumn{9}{|c|}{ Age groups (years) } \\
\hline \multirow{3}{*}{$\begin{array}{l}\text { Status } \\
\text { (n) }\end{array}$} & \multicolumn{2}{|l|}{$<2$} & \multicolumn{2}{|l|}{$2-3$} & \multicolumn{2}{|l|}{$4-6$} & \multicolumn{2}{|l|}{ Total } \\
\hline & Patients & $\begin{array}{l}\text { Control } \\
\text { subjects }\end{array}$ & Patients & $\begin{array}{l}\text { Control } \\
\text { subjects }\end{array}$ & Patients & $\begin{array}{l}\text { Control } \\
\text { subjects }\end{array}$ & Patients & $\begin{array}{l}\text { Control } \\
\text { subjects }\end{array}$ \\
\hline & 11 & 11 & 22 & 22 & 57 & 57 & 90 & 90 \\
\hline $\begin{array}{l}\mathrm{IgG} \\
(\mathrm{EIU})\end{array}$ & $17 \pm 11$ & $42 \pm 14$ & $48 \pm 11$ & $31 \pm 11$ & $44 \pm 6$ & $42 \pm 6$ & $42 \pm 5$ & $39 \pm 5$ \\
\hline $\begin{array}{l}\mathrm{IgM} \\
\text { (EIU) }\end{array}$ & $4 \pm 1$ & $9 \pm 2$ & $14 \pm 3$ & $14 \pm 3$ & $18 \pm 2$ & $15 \pm 2$ & $15 \pm 1$ & $14 \pm 1$ \\
\hline $\begin{array}{l}\text { IgA } \\
\text { (EIU) }\end{array}$ & $12 \pm 5$ & $13 \pm 6$ & $18 \pm 4^{\mathrm{a}}$ & $8 \pm 1$ & $14 \pm 1^{b}$ & $9 \pm 1$ & $15 \pm 1^{c}$ & $9 \pm 1$ \\
\hline
\end{tabular}

Results are give as mean \pm SEM.

${ }^{a} p<0.05$ vs control subjects; ${ }^{b} p<0.005$ vs control subjects; ${ }^{c} p<0.005$ vs control subjects

tients and in 2 of $90(2 \%)$ control subjects CMV IgA was positive but CMV IgG was negative (Fig.2). No correlation was found between CMV IgA and age. The levels of ICA and CMV IgG, IgM or IgA did not correlate at the diagnosis of diabetes in the patients, and the mean ICA levels did not differ between CMV IgG positive and negative patients ( $210 \pm 7$ vs $204 \pm 60$ JDF units). This was true also when the effect of age on ICA positivity was excluded in the analysis of multiple regression. All control children were ICA negative.

Diabetic children who were diagnosed very young (before the age of 2 years, the youngest being 0.8 years of age) were analysed in more detail to ascertain possible signs of CMV infection in early life. Of these 32 patients $10(31 \%)$ were positive for CMV IgG but none for CMV IgM. ICA was analysed in all of these 32 patients. The majority $(n=30)$ were ICA positive including $10 \mathrm{CMV}$ IgG positive and $20 \mathrm{CMV}$ IgG negative patients, and the remaining two ICA negative patients were also CMV IgG negative. The levels of ICA did not correlate with CMV IgG, IgM or IgA levels. For 11 of these $32 \mathrm{pa}-$ tients an age- and sex matched control subject was available (Table 2). All these 11 pairs were CMV IgM negative. In five pairs both the diabetic patient and the control subject were IgG negative and in two pairs IgG positive, respectively. The remaining four pairs were discordant for CMV $\operatorname{IgG}$; all diabetic patients were $\operatorname{IgG}$ negative and the control subjects IgG positive.

\section{Discussion}

The purpose of this study was to prospectively investigate the number of primary CMV infections before the onset of clinical IDDM and the possible temporal association between CMV infections and the appearance of ICA. Serological methods used in the present study have previously been shown to be use- ful in the diagnosis of primary but also reactivated CMV infections and CMV IgG, IgM and IgA antibodies have all been detected in primary, convalescent and recurrent infections [11]. $\operatorname{IgG}$ antibodies normally peak during the first month or two after the onset of infection [12] and IgM during the early course of infection [8]. In recurrent CMV infections IgG usually rises while $\operatorname{IgM}$ is rarely detectable [11]. CMV IgA has been found in sera of both acute and convalescent patients and it has been considered to be a marker of CMV reactivation when $\operatorname{IgM}$ is absent [11].

The role of CMV in the pathogenesis of IDDM has been proposed in some earlier reports [2-5, 13]. However, such a connection has not been found in all studies, for example in two separate reports there was no evidence of recent CMV infection in patients with newly-diagnosed IDDM $[14,15]$. Also, in the present study, CMV IgG and IgM were not different in newly-diagnosed diabetic children and control subjects, and the proportion of seronegative patients was relatively high $(53 \%)$. This suggests that CMV is not a common precipitator of clinical IDDM. However, CMV IgA was higher in these patients compared to control children. This could reflect reactivated or persistent $\mathrm{CMV}$ infections in newly-diagnosed diabetic patients. On the other hand, $\operatorname{Ig} A$ was not different in IgG positive patients and control subjects and it did not rise before the diagnosis of diabetes or before ICA seroconversions during the follow-up of initially unaffected siblings of IDDM patients. Also the observation that CMV IgG was not different in diabetic patients and control subjects suggests an equal exposure to CMV in the past and argues against an over-representation of patients with chronic forms of CMV infections. Thus, higher CMV IgA in diabetic patients may reflect non-specific $\operatorname{Ig} A$ reactivity in these children.

Comparison of antibodies between patients and control subjects at the time of the diagnosis of diabetes has some disadvantages. The initial virus infec- 

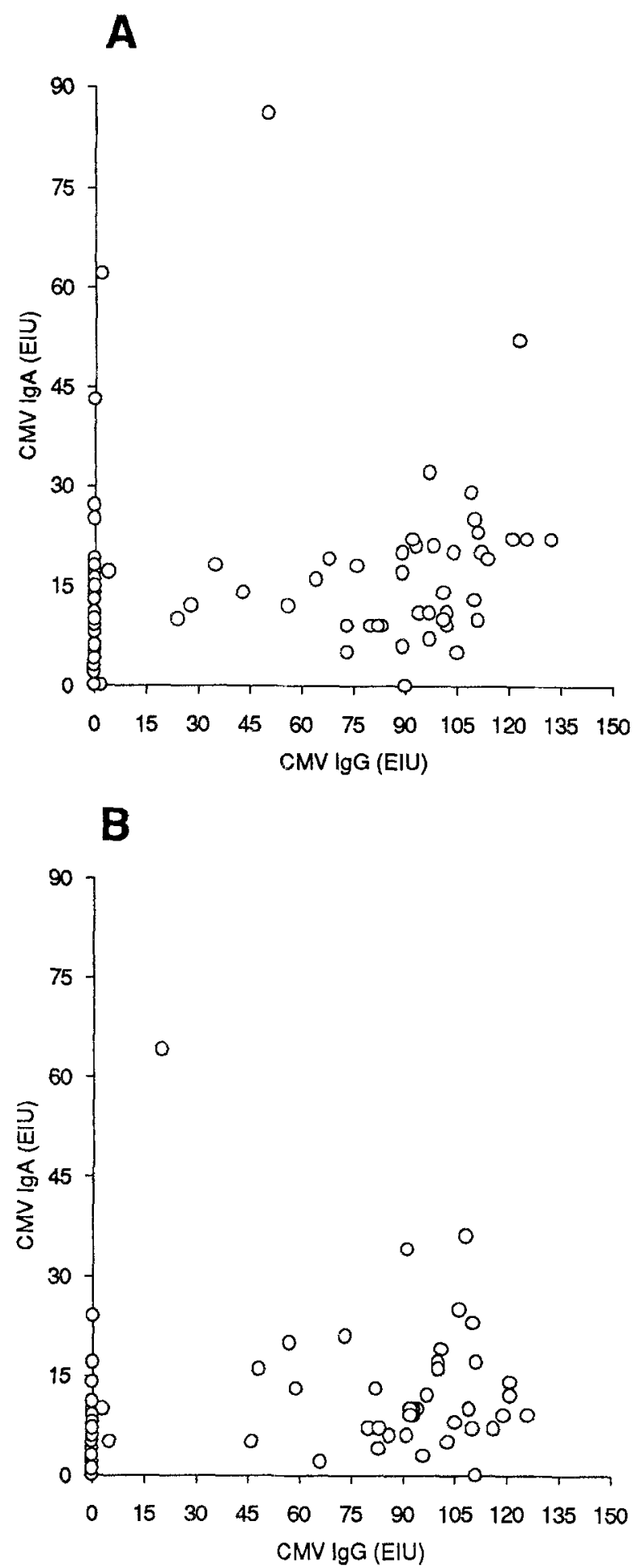

Fig. 2. (A, B) Plot of CMV IgA antibodies vs CMV IgG antibodies: (A) 90 newly-diagnosed IDDM patients; (B) 90 age and sex-matched control subjects

tion may have occurred very early in life, or even before birth, and the signs of the infection may already be lost by the time of the diagnosis of diabetes. The onset of clinical diabetes might also promote reactivation of CMV which may result in elevation of antibody levels in newly-diagnosed patients. Therefore, we carried out a prospective time-series on siblings of diabetic children during several years before the manifestation of clinical IDDM. This was possible due to the unique collection of sera during the follow-up of originally healthy siblings of newly-diagnosed IDDM patients.

Cytomegalovirus can be transmitted in utero as a consequence of both primary and reactivated maternal infections [16]. Primary CMV infection during pregnancy poses a $30-50 \%$ risk of intrauterine transmission $[17,18]$, whereas this seems to be very rare in reactivation of latent infections [17]. Fetal infection is more virulent when acquired during the first half of gestation when it may lead to the congenital CMV syndrome $[17,18]$. In a Swedish prospective study of congenital CMV infection no evidence was found for congenital CMV infection and IDDM being related [19]. We found no evidence of primary maternal CMV infections during the first 3 months of pregnancy in mothers who gave birth to a subsequently diabetic child suggesting no role of in utero CMV exposure in the pathogenesis of IDDM. Further support for this finding was obtained by studying a subgroup of very young diabetic patients diagnosed before the age of 2 years in which we observed no excess of CMV IgG or signs of recent primary CMV infections. In fact, among these very young children the control subjects were more often positive for CMV IgG than the patients.

No signs of primary CMV infections were seen preceding the diagnosis of IDDM or ICA seroconversions during the follow-up of initially healthy siblings of IDDM patients. More than a third of the observed siblings ( $37 \%$ ) had never contracted CMV according to negative CMV $\mathrm{IgG}$ and still, they turned ICA seropositive or presented with IDDM. Half of the siblings who contracted diabetes during the follow-up were constantly seronegative as were also $53 \%$ of the newly-diagnosed diabetic children. There was also no correlation between ICA and CMV antibodies. The majority ( $75 \%$ ) of the siblings who became ICA positive during the follow-up had already been infected by CMV before the start of the follow-up, and the rest of them were constantly seronegative. Accordingly, in these siblings primary CMV infections were not temporarily associated with ICA seroconversions. Seroprevalence for CMV $\mathrm{IgG}$ was relatively high in pregnant mothers (78\%) and in the very young $(31 \%)$ diabetic children. The frequencies of $\mathrm{CMV} \operatorname{IgG}$ seropositive individuals were similar to those reported earlier in the Finnish population indicating that about $40 \%$ of children have had CMV infection already during their first year of life [20].

Taken together no evidence was found that primary CMV infections could promote or precipitate IDDM. We conclude that if CMV has a role in the pathogenesis of IDDM at all, it is limited to a small proportion of subjects. 
Acknowledgements. The authors gratefully acknowledge Dr. P. Koskela for sera of pregnant mothers, Dr. K. Hedman for avidity analysis and Ms. E. Jokela for expert technical assistance. This work was supported by grants from Reino Lahtikari Foundation, Nordisk Insulin Foundation Committee, University of Tampere and the Juvenile Diabetes Foundation International (grant 188517). The Childhood Diabetes in Finland-project has been supported by grants from NIH (DK 37957), Association of Finnish Life Insurance Companies, Sigrid Juselius Foundation and University of Helsinki.

The Childhood Diabetes in Finland (DiMe) Study Group is composed of the following members:

Principal investigators: H. K. Åkerblom, J. Tuomilehto

Co-ordinators: R. Lounamaa, L. Toivanen, E. A. Kaprio

Local investigators: A. Fagerlund, M. Flittner, B.Gustafsson,

C.Häggqvist, A.Hakulinen, L.Herva, P.Hiltunen,

T.Huhtamäki, N.-P.Huttunen, T.Huupponen, M.Hyttinen, T.Joki, R.Jokisalo, M.-L. Käär, S. Kallio, E.A.Kaprio, U.Kaski, M.Knip, L.Laine, J.Lappalainen, J.Mäenpää, A.L. Mäkelä, K. Niemi, A.Niiranen, A. Nuuja, P.Ojajärvi, T.Otonkoski, K.Pihlajamäki, S.Pöntynen, J.Rajantie, J.Sankala, J.Schumacher, M.Sillanpää, M.-R.Ståhlberg, C.H.Stråhlmann, T. Uotila, M. Väre, P. Varimo, G. Wetterstrand.

\section{References}

1. Alford CA, Britt WJ (1990) Cytomegalovirus. In: Fields BN, Knipe DM, Chanock RM et al. (eds) Fields Virology, Vol. 2. Raven Press, New York, p 1981

2. Pak CY, Eun H-M, McArthur RG, Yoon JW (1988) Association of cytomegalovirus infection with autoimmune type 1 diabetes. Lancet I: $1-4$

3. Nicoletti F, Scalia G, Lunetta M et al. (1990) Correlation between islet cell antibodies and anti-cytomegalovirus $\operatorname{IgM}$ and $\operatorname{IgG}$ antibodies in healthy first-degree relatives of type 1 (insulin-dependent) diabetic patients. Clin Immunol Immunopathol 55: 139-147

4. Pak CY, Cha CY, Rajotte RV, McArthur RG, Yoon JW (1990) Human pancreatic islet cell specific 38 kilodalton autoantigen identified by cytomegalovirus-induced monoclonal islet cell autoantibody. Diabetologia 33: 569-572

5. Jenson AB, Rosenberg HS, Notkins AL (1980) Pancreatic islet-cell damage in children with fatal viral infections. Lancet II: $354-358$

6. Tuomilehto J, Lounamaa R, Tuomilehto-Wolf E et al. and the Childhood Diabetes in Finland (DiMe) Study Group (1992) Epidemiology of childhood diabetes mellitus in Finland - background of a nationwide study of type 1 (insulindependent) diabetes mellitus. Diabetologia 35: 70-76

7. Turunen H, Vuorio KA, Leinikki PO (1983) Determination of $\operatorname{IgG}, \operatorname{IgM}$ and $\operatorname{IgA}$ antibody responses in human toxo- plasmosis by enzyme-linked immunosorbent assay (ELISA). Scand J Infect Dis 15: 307-311

8. Griffiths PD, Stagno S, Pass RF, Smith RJ, Alford CA, Jr. (1982) Infection with cytomegalovirus during pregnancy: specific IgM antibodies as a marker of recent primary infection. J Infect Dis 145: 647-653

9. Blackburn NK, Besselaar TG, Schoub BD, O'Connell KF (1991) Differentiation of primary cytomegalovirus infection from reactivation using the urea denaturation test for measuring antibody avidity. J Med Virol 33: 6-9

10. Knip M, Vähäsalo P, Karjalainen J, Lounamaa R, Akerblom HK and the Childhood Diabetes in Finland Study Group (1994) Natural history of preclinical IDDM in high risk siblings. Diabetologia 37: 388-393

11. Doerr HW, Rentscler M, Scheifler G (1987) Serological detections of active infections with human herpes viruses (CMV, EBV, HSV, VZV): diagnostic potential of IgA class and $\mathrm{IgG}$ subclass-specific antibodies. Infection 15: 93-98

12. Linde GA, Hammarström L, Persson MAA, Smith CIE, Sundqvist V-A, Wahren B (1983) Virus-specific antibody activity of different subclasses of immunoglobulins $G$ and $A$ in cytomegalovirus infections. Infect Immun 42: 237244

13. Ward KP, Galloway WH, Auhterlonie IA (1979) Congenital cytomegalovirus infection and diabetes. Lancet I: 497 (Letter)

14. Banatvala JF, Bryant J, Schernthaner G et al. (1985) Coxsackie B, mumps, rubella, and cytomegalovirus specific IgM responses in patients with juvenile-onset insulin-dependent diabetes mellitus in Britain, Austria, and Australia. Lancet I: $1409-1412$

15. Pagano G, Cavallo-Perin P, Cavalot F et al. (1987) Genetic, immunologic, and environmental heterogeneity of IDDM. Incidence and 12-mo follow-up of an Italian population. Diabetes 36: 859-863

16. Stagno S, Pass RF, Dworsky ME et al. (1982) Congenital cytomegalovirus infection. The relative importance of primary and recurrent maternal infection. N Engl J Med 306: 945-949

17. Stern H, Tucker SM (1973) Prospective study of cytomegalovirus infection in pregnancy. BMJ 2: 268-270

18. Stagno S, Pass RF, Cloud G et al. (1986) Primary cytomegalovirus infection in pregnancy. Incidence, transmission to fetus and clinical outcome. JAMA 256: 1904-1908

19. Ivarsson S-A, Lindberg B, Nilsson KO, Ahlfors K, Svanberg L (1993) The prevalence of type 1 diabetes mellitus at follow-up of Swedish infants congenitally infected with cytomegalovirus. Diabet Med 10: 521-523

20. Leinikki P, Granström M-L, Santavuori P, Pettay O (1978) Epidemiology of cytomegalovirus infections during pregnancy and infancy. A prospective study. Scand J Infect Dis 10: $165-171$ 